\title{
Dirsek kırıklı çıkıkları: genel yaklaşım ve sınıflama
}

\author{
Fracture dislocations of the elbow: overview and classification
}

\author{
Ufuk Nalbantoğlu, Arel Gereli
}

Acıbadem Üniversitesi Tıp Fakültesi, Ortopedi ve Travmatoloji Anabilim Dalı, İstanbul

\begin{abstract}
Dirsek bölgesi kırıklı çıkıkları karmaşık yaralanmalardır ve yanlış tanı konulduğunda sorun daha da karmaşık hale gelir. Eşlik eden olası yaralanmaları tanımak için, müdahale öncesinde tüm radyolojik değerlendirmelerin ayrıntılı bir şekilde incelenmesi gerekir. Bu değerlendirmeler direkt grafileri, bilgisayarlı tomografiyi (BT) ve imkan varsa üç boyutlu BT'yi içermelidir. Bu yaralanmalar beş ana başlıkta değerlendirilebilir: (1) dirsek çıkığı ve radius başı kırı̆̆ı, (2) dirsek çıkığı ve anteromediyal koronoid kırığı (varus posteromediyal instabilite), (3) dirsek çıkığı ve radius başı ile koronoid kırığı (korkunç üçlü), (4) öne dirsek çıkığı ve ulna üst uç kırığı (transolekranon) ve (5) arkaya dirsek çıkığı ve ulna üst uç kırığı (Monteggia yaralanması). Yaralanmanın tam olarak tanımlanması tedavi hazırlığı için anahtardır. Dirsek kırıklı çıkıklarında her bir alt tipin kendine özgü bileşenleri vardır. Kararlı bir dirsek eklemi elde etmek için bu bileşenler tam olarak tedavi edilmelidir.
\end{abstract}

Anahtar sözcülkler: dirsek; çıkıklar; kırıklı çıkıklar
Elbow fracture dislocation is a complex injury and may be more problematic if it is misdiagnosed. The preoperative radiographs should be carefully evaluated to recognize all lesions that may occur in elbow fracture dislocations. Evaluations must include $X$-rays, $C T$ scan and $3 D$ reconstruction if available. These injuries can be classified in five categories: (1) elbow dislocation with radial head fracture, (2) elbow dislocation with anteromedial coronoid fracture (varus posteromedial instability), (3) elbow dislocation with radial head and coronoid fracture (terrible triad injury), (4) anterior elbow dislocation with proximal ulna fracture (transolecranon), and (5) posterior elbow dislocation with proximal ulna fracture (monteggia lesion). Clear definition of injury is the key factor in the treatment strategy. Elbow fracture dislocations have specific components and each components should be addressed in order to achieve a stable elbow.

Key words: elbow; dislocations; fracture dislocations

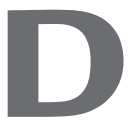
irsek kırıklı çıkığı, ulnotroklear eklemde çıkık ile birlikte dirseğin birincil kemik desteklerinden en az birinin kırık olduğu yaralanmaları tanımlar. Bu durumda dirsek çıkığına ulna üst ucu, radius başı, koronoid kırığı ya da bunların bileşimleri eşlik edebilir. Kırık sayısı arttıkça instabilite de artar. Dirsek çıkığı nedeniyle eşlik eden yumuşak doku yaralanması da düşünüldüğünde, bunlar ortopedik travmatolojinin en karmaşık yaralanmaları arasında sayılabilir. Bu yaralanmalar çoğunlukla cerrahi olarak tedavi edilir. Cerrahi dışı tedavi yöntemleri sonucu dirsek sertliği ve tekrarlayan çıkıklar beklenen artsorunlardır. ${ }^{[1]}$ Dirsek kırıklı çıkıklarında sonucu belirleyen etkenler; başarısız cerrahi girişim, gecikme (2 haftadan fazla), kırıkta parçalanma, travmanın şiddeti ve hastanın yaşıdır. ${ }^{[2]}$ Sayılan etkenlerden ilk ikisi değiştirilebilen etkenler olarak düşünülebilir.
Her halükarda, yaralanmayı oluşturan tüm bileşenlerin aynı zamanda ve erken dönemde tedavisi önemlidir; cerrahi tedavi planlanırken yaralanmanın tüm bileşenleri ortaya konmalıdır. Bu amaçla temel radyolojik tetkiklerin (3D grafiler) yanı sıra bilgisayarlı tomografi (BT) değerlendirmesi çok kıymetli bilgiler verebilir. Manyetik rezonans (MR) değerlendirmesinin ise akut yaralanma nedeniyle katkısı sınırıdır. Dirsek kırıklı çıkıkları tamamen instabil yaralanmalar olduğundan, ilk müdahale sırasında kapalı düzelmenin sağlanması ve devam ettirilmesi zor olabilir. Bu durumda, tekrarlayan girişimlerden kaçınılmalı ve dirseğin en rahat olduğu şekilde posterior atel tespiti ile cerrahi planlama yapılmalıdır. Dirsek kırıklı çıkıklarına özellikle ulnar sinir yaralanması eşlik edebilir. ${ }^{[3]}$ Açık kırıklı çıkıklarda eşlik eden brakiyal arter yaralanması akılda tutulmalıdır.

- İletişim adresi: Dr. Ufuk Nalbantoğlu, Acıbadem Üniversitesi Tıp Fakültesi, Ortopedi ve Travmatoloji Anabilim Dalı, İstanbul Tel: 0532 - 4946090 e-posta: drufukn@hotmail.com

- Geliș tarihi: 10 Ocak 2014 Kabul tarihi: 10 Ocak 2014 
Dirsek kırıklı çıkıkları için kabul görmüş bir sınıflama mevcut değildir fakat kırıkların yerine ve ön kolun humerusa göre olan durumuna göre tanımlanabilir. Bu yaralanmaları oluşturan her bir bileşen için ayrı sınıflama sistemleri mevcuttur ve bu şekilde sınıflama yapılmaktadır. Dirsek ekleminin travmaya verdiği yanıt özelleşmiş kemik/eklem yapısı ve yumuşak doku örtüsü nedeni ile geniş bir yelpaze içinde değişik şekillerde sonuçlanır. Dirsek kırıklı çıkıkları da bu yelpaze içinde beş farklı yaralanma başlığında değerlendirilebilir: (1) Dirsek çıkığı ve radius başı kırığı, (2) dirsek çıkığı ve anteromediyal koronoid kırığı (varus posteromediyal instabilite), (3) dirsek çıkı ̆̆ı, radius başı kırığı ve koronoid kırı̆̆ı (korkunç üçlü), (4) ulna üst uç kırığı ve anterior dirsek çıkığı (transolekranon kırıklı çıkığı) ve (5) ulna üst uç kırığı ve posterior dirsek çıkığı (Monteggia benzeri yaralanma).

\section{DIRSEK ÇIKIĞI VE RADIUS BAŞI KIRIĞI}

Dirsek çıkığı ve radius başı kırığı en sık görülen kırıklı çıkık şeklidir. Genel olarak dirsek ekstansiyonda iken açık el ayası üzerine düşme sonrası oluşur. Dirsek çıkı̆̆ı nedeniyle radius başı kırığına lateral-kollateral, mediyal-kollateral ya da çoklu bağ yaralanması da eşlik eder. ${ }^{[4,5]}$ Lateral kollateral bağ yaralanması tipik olarak humerustaki izometrik yapışma noktasından kopma şeklindedir (Şekil 1). ${ }^{[6]}$ Mediyal-kollateral bağ yaralanması varlığında ise radius başının tamiri ya da yerine konması daha da önem kazanır. Radius başının çarpması nedeniyle kapitellumda kıkırdak yaralanması da görülebilir. ${ }^{[7]}$
Bu yaralanmalarda radius başı kırı̆̆ı için Mason sınıflaması kullanılır. ${ }^{[8]}$ Parçaların büyüklüğü ve kayma derecesine göre Tip I yaralanma, çok az kayma gösteren $(<2 \mathrm{~mm})$ ya da kayma göstermeyen kırıkları; Tip II, 2 mm'den fazla kayan ve başın \%30'undan fazlasını tutan kırıkları; Tip III ise parçalanma gösteren kırıkları tanımlar. Mason sınıflamasına yeni bir ekleme ile, dirsek çıkığının eşlik ettiği radius başı kırıkları Tip IV yaralanmalar olarak sınıflanmıştır (Şekil 2). Bu sınıflama yöntemi tedavi planından çok tanımlamaya dayalıdır. Tedaviye yönelik benzer bir sınıflamada ise Tip I, yaralanma çok az kayma gösteren $(<2 \mathrm{~mm})$ ya da kayma göstermeyen kırıkları; Tip II, kayma gösteren ama osteosentezin mümkün olduğu kırıkları; Tip III ise osteosenteze imkan vermeyen kırıkları tanımlamaktadır. ${ }^{[9]}$ Bu yaralanmalarda radius başının eksizyonu kontrendikedir. Tedavide radius başına osteosentez/protez uygulaması ve lateralkollateral bağ tamiri çoğu kez yeterli olur. Buna rağmen mediyal-kollateral yetmezliği saptanırsa, tedaviye mediyal bağ tamiri de eklenmelidir. ${ }^{[4,10]}$

\section{DIRSEK ÇIKIĞI VE ANTEROMEDIYAL KORONOID KIRIĞI}

\section{(Varus posteromediyal instabilite)}

Ön kol pronasyonda ve dirsek ekstansiyonda iken oluşan aksiyel yüklenme, ön kolda posteromediyal rotasyonel zorlanma ve dirsek ekleminde varus zorlanmasına neden olur. Bu zorlanma ile koronoid çıkıntının özellikle anteromediyal eklem yüzü yüklenmeye maruz kalır. Lateral bağların yırtılması ile tüm yük koronoidin anteromediyaline biner ve zayıf metafizer kemik

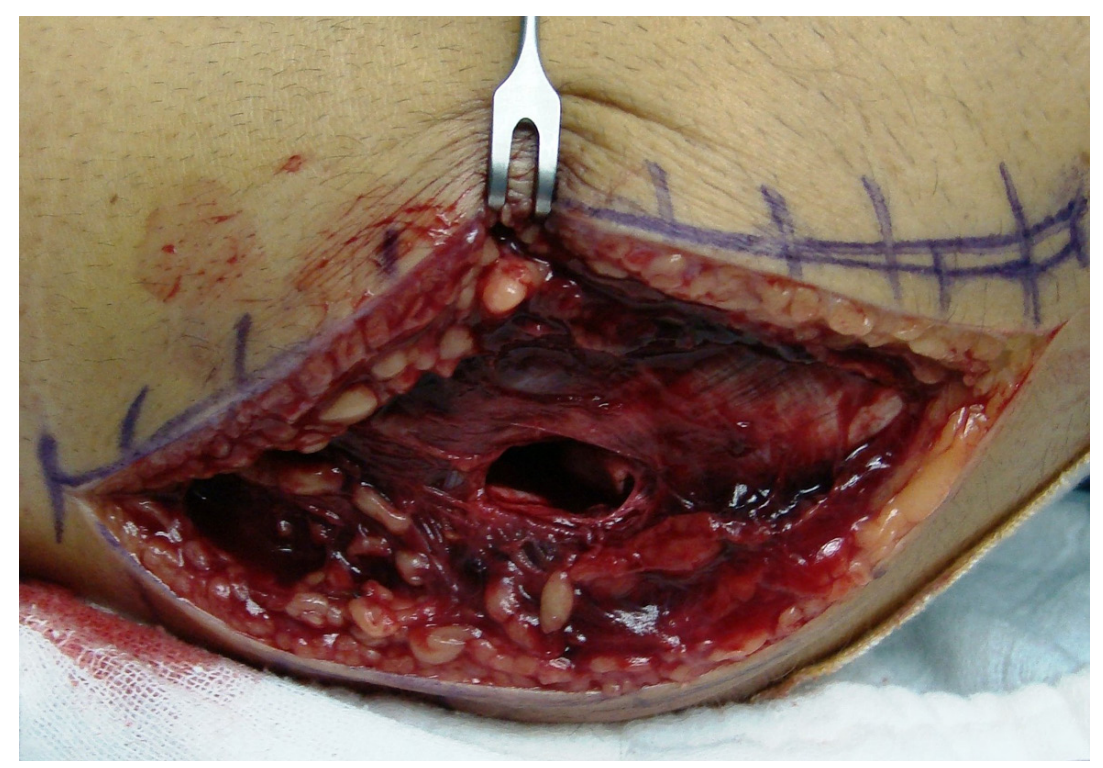

Şekil 1. Dirsek çıkığı sonrası lateral yapılar genelde humerustan ayrılır. 

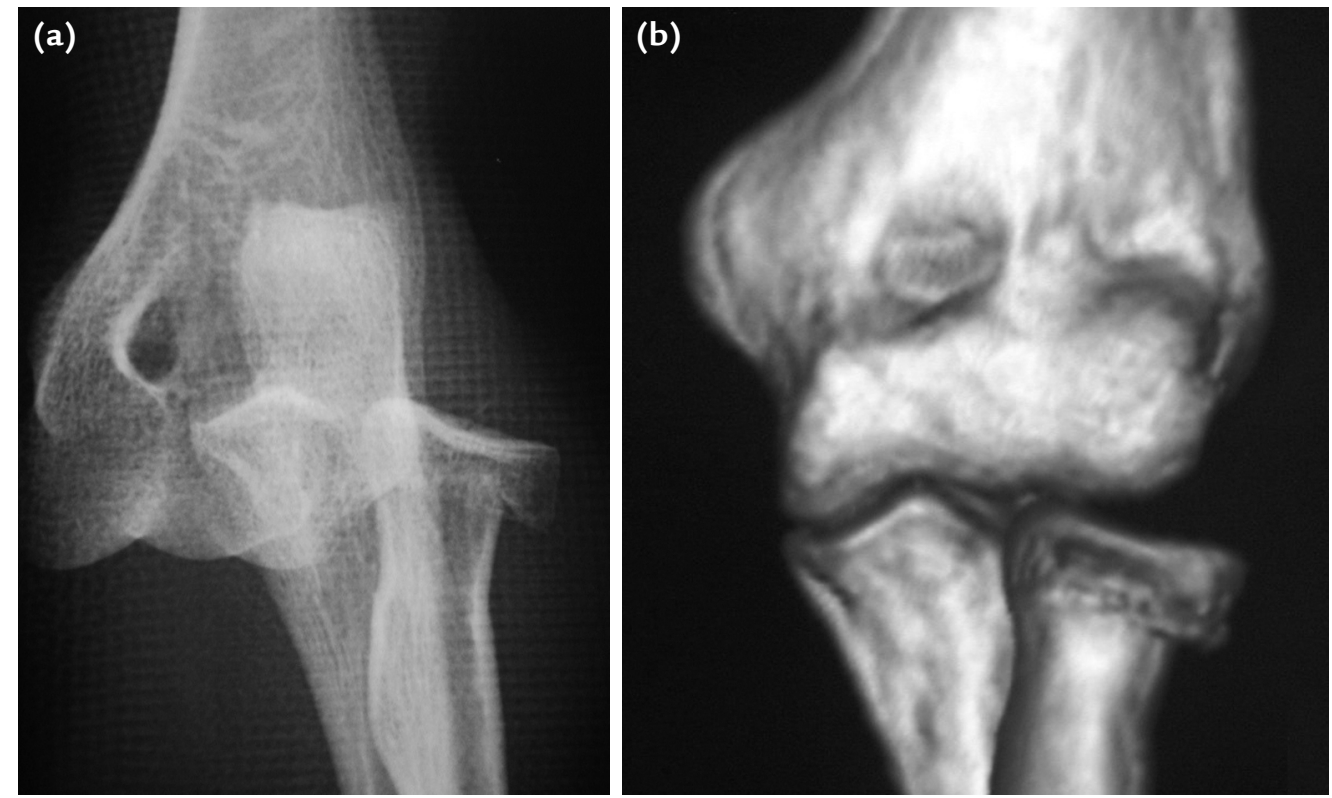

Şekil 2. a, b. Dirsek çıkığı ile birlikte radius başı kırığı radyografisi (a) ve üç boyutlu BT görüntüsü (b).

desteğinin de katkısı ile trokleanın mediyali tarafından ezilerek kırılır. ${ }^{[11]}$ Bu kırıklar dirsek grafilerinde dikkat çekmeyebilirler ancak kırığın yeri itibariyle dirsek instabilitesine neden olabilir (Şekil 3).

Dirseğin posteromediyal varus instabilitesi anlaşıldıkça, koronoidin anteromediyal eklem yüzü özel ilgi görmeye başlamıştır. Koronoid kırıklarında dirsek grafisine dayanan sınıflama sistemleri bu yaralanmaları tanımlayamadığından, BT'ye dayanan sınıflama

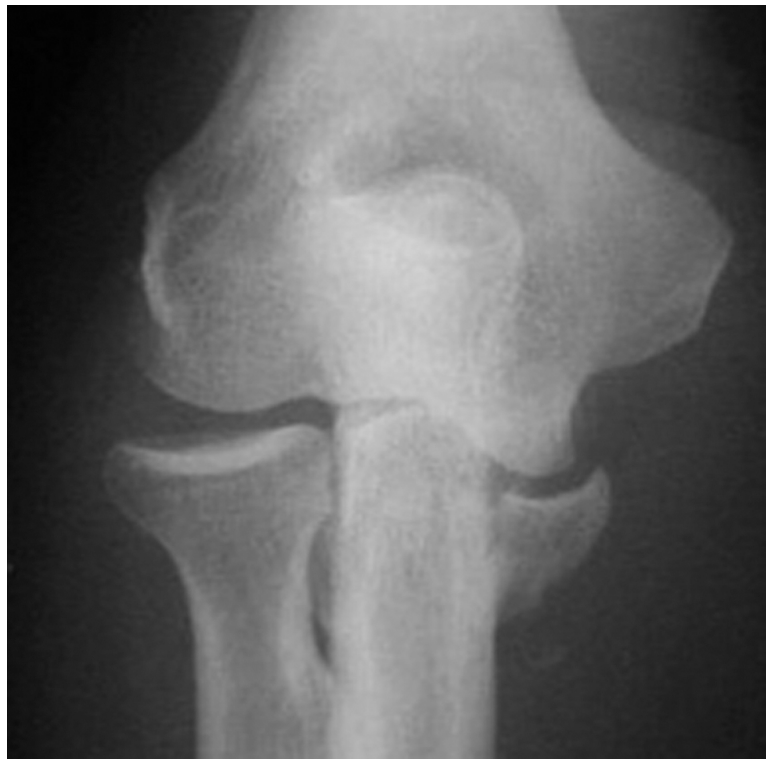

Şekil 3. Anteromediyal koronoid kırı̆̆ı ve posteromediyal instabilite. sistemleri geliştirilmiştir. O'Driscoll tarafından yapılan sınıflama sisteminde anteromediyal koronoid kırıkları ayrı bir başlıkta incelenmiştir;; ${ }^{[2]}$ her ne kadar günlük kullanımı zor olsa da, anteromediyal kırıkları değerlendiren yegane sınıflama sistemidir (Tablo 1). Bu sınıflama sistemi kırığın anatomik yerleşimine göre yapılmıştır ve karmaşık dirsek kırıklı çıkıklarının alt tiplerine özgü koronoid kırık şekillerini üç ana başlık altında tanımlamaktadır. Birinci grup, koronoid uç kırıklarını içerir ve kötü üçleme tipi yaralanmalara uyar; ikinci grupta, koronoid anteromediyal kırıkları vardır ve varus posteromediyal instabilite yaralanmalarına uyar; üçüncü grupta ise koronoidin bazal kırıkları vardır ve olekranon kırıklı çıkık yaralanmalarına uyar. Koronoidin anteromediyal kırıkları, posteromediyal rotasyonel instabiliteye işaret etmesi açısından özel önem taşımaktadır. Bu kırıkların yetersiz tedavisi, dirsek ekleminde dizilim bozukluğuna, çıkma eğilimine ve buna bağlı erken gelişen artroza neden olabilir. ${ }^{[12-15]}$

\section{DIRSEK ÇIKIĞI, RADIUS BAŞI KIRIĞI VE KORONOID KIRIĞI}

(Korkunç üçlü)

$\mathrm{Bu}$ yaralanmalar, valgus posterolateral rotasyonel instabilitenin daha ağır bir şeklidir. Dirsek fleksiyonda ve ön kol supinasyonda iken aksiyel yüklenme ve valgus zorlaması ile oluşur. Bu yüklenme lateralden mediyale doğru ilerleyerek lateral yan bağda kopma, radius başında değişik derecelerde kırık, koronoid çıkıntı kırı̆̆ı (genelde küçük parçalı), iç yan bağda kopma/yaralanma 
Tablo 1. Koronoid kırıklarında O'Driscoll sınıflaması

\begin{tabular}{lcl}
\hline Kırık tipi ve yeri & Altsınıf & Tanımlama \\
\hline Uç & 1 & 2 mm'den küçük kırık \\
& 2 & 2 mm'den büyük kırık \\
& 1 & Anteromediyal dudak \\
Anteromediyal & 2 & Anteromediyal dudak ve uç \\
& 3 & Anteromediyal dudak + sublim tuberkul \pm uç kırı̆ı \\
Taban & 1 & Koronoidde gövde ve taban kırığı \\
& 2 & Geniş tabanlı koronoid kırığı (transolekranon)
\end{tabular}

ve dirsek çıkığı ile sonuçlanır (Şekil 4). Dirseğin tüm yumuşak doku ve kemik desteklerinin yaralanmasını içerdiğinden 'korkunç üçlü' olarak isimlendirilir ve yüksek artsorun olasılığı ile birliktedir. ${ }^{[8]}$

$\mathrm{Bu}$ yaralanmalar için tek bir sınıflama sistemi yoktur. Bileşenleri ayrı ayrı sınıflanır. Dış yan bağ genelde humerustaki yapışma yerinden avulsiyon şeklinde kopar. Radius başı için Mason sınıflaması kullanılır. Koronoid kırığı için Regan-Morrey sınıflama sistemi en pratik sınıflama sistemidir. ${ }^{[16]}$ Bu sistem koronoid kırığının lateral dirsek grafisindeki görüntüsüne dayanır. Tip I kırıklar koronoidin uç kırıklarını tanımlar. Tip II kırıklar koronoid yüksekliğinin \%50'den azını ilgilendirirken, Tip III kırıklar koronoidin lateral yüksekliğinin \%50'den fazlasını ilgilendirir. BT'nin yaygın kullanımı ile koronoid kırıklarının sadece transvers planda değil daha oblik şekillerde de olabildiği anlaşılmıştır. Bu tip kırıkları içermeyen Regan-Morrey sınıflamasına son zamanlarda yeni bir tip eklenerek güncelleme yapılmıştır.
Mediyal oblik veya lateral oblik kırıklar için Tip IV mediyal veya Tip IV lateral grubu eklenmiştir. ${ }^{[17]}$

Yapılan çalışmalar sonucu 'korkunç üçlü' yaralanmalarında büyük oranda başarılı sonuç verebilen bir tedavi planı kabul görmüştür. ${ }^{[18,19]}$ Bu yaklaşımda tedavi öncelikle lateralden başlar ve içten dışa doğrudur. Eğer tespit gerektiriyorsa, koronoidin lateralden tespiti veya küçük parçaların kapsül ile birlikte dikilmesi, radius başı tamiri/protezi ve en son lateral yan bağ tamiri yapılır. Buna rağmen instabilite sürüyorsa mediyal yan bağ tamiri eklenir. Dirsek hâlâ instabil ise tedaviye eksternal fiksatör eklenmelidir.

\section{ULNA ÜST UÇ KIRIĞI VE ANTERIOR DIRSEK ÇIKIĞI \\ (Transolekranon kırıklı çıkığı)}

Transolekranon kırıklı çıkığı, genç erişkin hastalarda dirsek fleksiyonda iken ön kol proksimaline
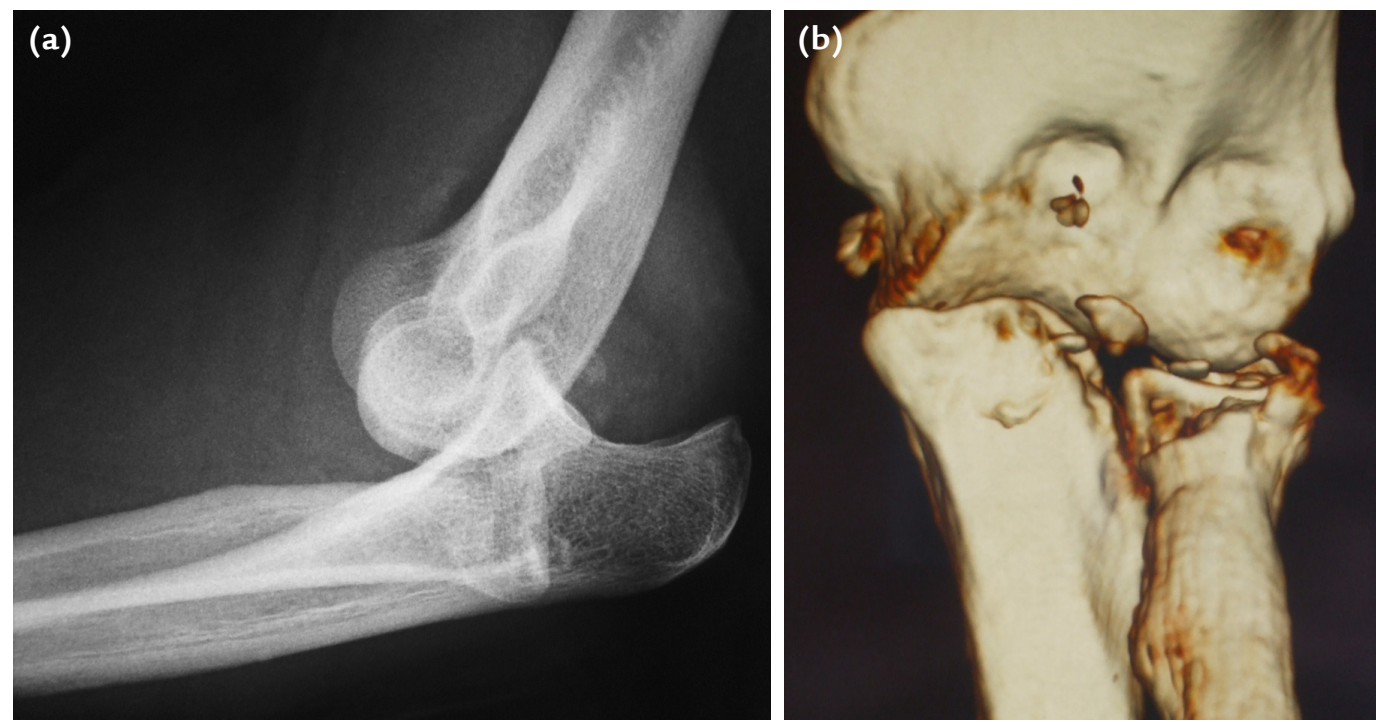

Şekil 4. a, b. Kötü üçleme yaralanması (a) ve küçük parçalı koronoid kırığı (b). 


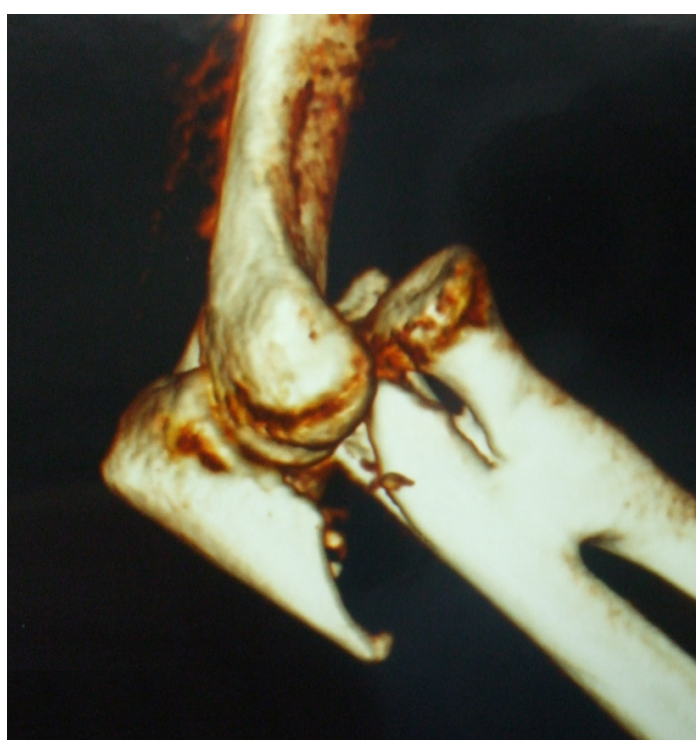

Şekil 5. Transolekranon kırıklı çıkı̆̆ı.

posteriordan doğrusal yüklenmeler sonrası görülür ve yüksek enerjili yaralanmalardır. Ulna üst ucu, troklear çentik ve olekranonda parçalı kırık nedeni ile ulnotroklear ilişki bozulmuştur. Buna bağlı koronoidde geniş tabanlı kırık görülürken radius başı sağlam kalır. Proksimal radyoulnar eklem ilişkisi bozulmadan radius kapitelluma göre anteriora yer değiştirir (Şekil 5). Bu yaralanmalar, Monteggia benzeri kırıklı çıkıklardır. ${ }^{[20]}$ Kendilerine ait bir sınıflama olmadığından, Monteggia kırıklı çıkıkları için kullanılan Bado sınıflaması kapsamında değerlendirilebilir. ${ }^{[21]}$ Bado sınıflamasında Tip I yaralanma, ulna diyafizinde anterior açılanmalı kırık ve radius başının anterior çıkığını tanımlar; Tip II, ulna diyafizinde posterior açılanmalı kırık ile radius başının posterior çıkığını içerir; Tip III, ulna kırığı ile radius başının laterale çıkığını; Tip IV ise radius başı çıkığı ile birlikte ulna ve radiusta aynı seviyeli kırığı tanımlar. Transolekranon kırıklı çıkıkları Bado Tip I yaralanmalara benzeseler de, bu yaralanmalarda proksimal radyoulnar ilişki çoğu kez korunmuştur. ${ }^{[22]}$ Tip I Monteggia yaralanmalarında ise transolekranon kırıklı çıkıklarından farklı olarak ulnohumeral eklem bütünlüğü bozulmaz. Transolekranon kırıklı çıkık görülen hastalarda ulnotroklear eklemde parçalanma görülmesine rağmen yaralanma esasen kemiğe sınırlı kalmaktadır ve bu bölgede kemiğin güçlü sistemlerle yapılandırılması başarılı sonuç için çoğu kez yeterlidir. ${ }^{[23]}$

\section{ULNA ÜST UÇ KIRIĞI VE POSTERIOR DIRSEK ÇIKIĞI}

Ulna üst uç kırı̆̆ı ve posterior dirsek çıkığı, yaşlı hasta grubunda ve osteoporotik kemikte daha düşük enerjili yaralanmalar sonucu görülebilir. Ulnada, posteriora açılanmalı kırıkla birlikte radius başında kapitelluma göre posteriora çıkık görülür. Bu haliyle, Tip II Monteggia kırıklı çıkıkları ile aynı yaklaşımla tedavi edilebilir. Ulna üst uçta parçalı kırık nedeni ile koronoidde geniş tabanlı kırık ve radius başı kırığı yaralanmaya eşlik eder. Ulnotroklear eklem tutulabilir veya tutulmayabilir (Şekil 6). Yumuşak doku ve bağ (özellikle dış yan bağ) yaralanması, transolekranon yaralanmalarından farklı olarak çoğu kez mevcuttur. ${ }^{[2]} 1991$ yılında Jupiter ve arkadaşları bu yaralanmaları daha iyi sınıflamak için, Monteggia Tip II kırıklı çıkıklarına dört yeni

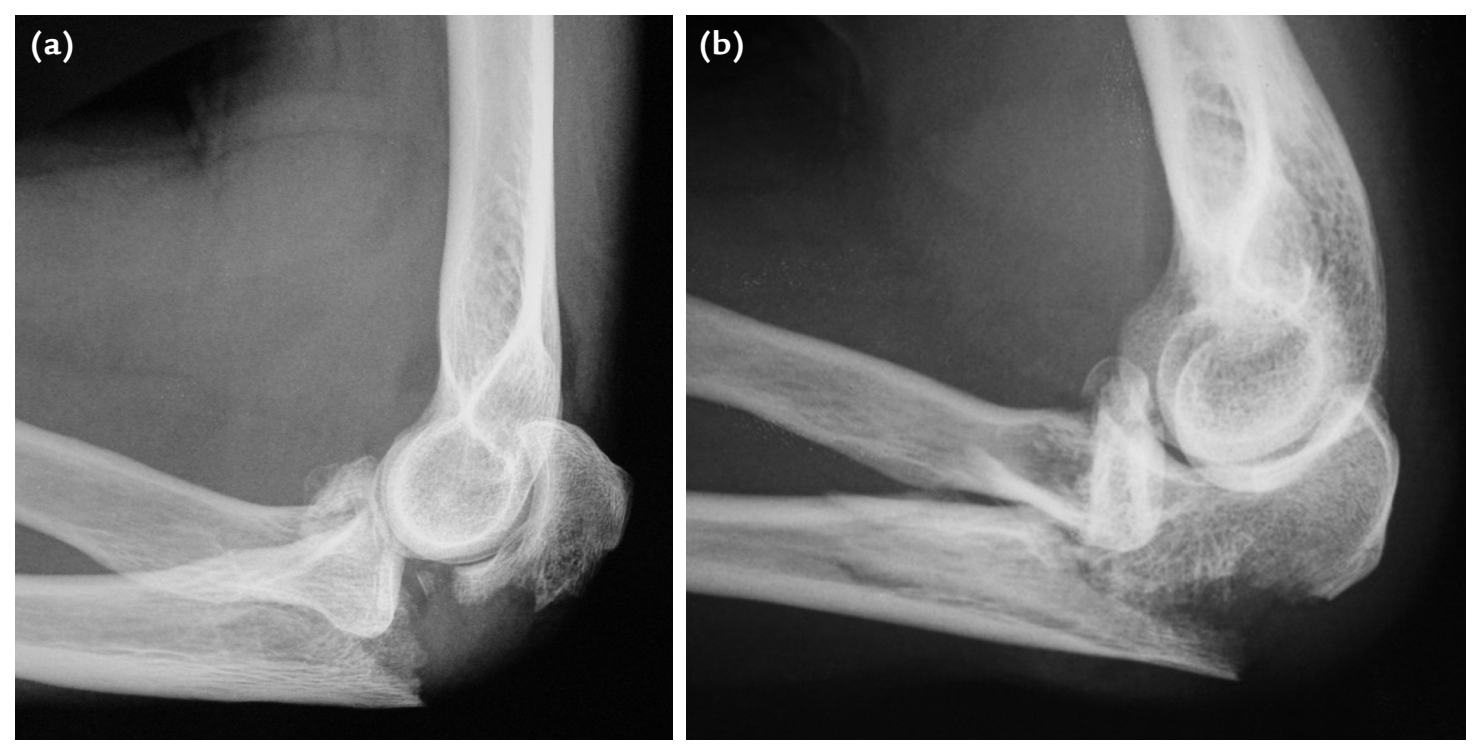

Şekil 6. a, b. Ulna üst uç kırığı ve posterior dirsek çıkığı. Ulnotroklear ilişkinin bozulduğu (a) ve korunduğu (b) yaralanma. 
alt grup eklemişlerdir. ${ }^{[24]}$ Tip IIA, troklear çentik seviyesindeki kırığı; Tip IIB, proksimal ulna metafizodiyafizer bileşkedeki kırığı (koronoidin distalinde); Tip IIC, ulna diyafizindeki kırı̆̆ı ve Tip IID, birden fazla bölgeyi ilgilendiren parçalı kırığı tanımlar. Bu yaralanmalar, transolekranon kırıklı çıkıklarından farklı olarak, hem kemik hem de yumuşak dokuyu ilgilendirir ve prognozları daha kötüdür. Dirsek ekleminde gizli kalmış instabilite ve buna bağlı eklem artrozu görülebilir. ${ }^{[25]}$

Dirsek kırıklı çıkıkları, dirsek ekleminin travmaya verdiği yanıt yelpazesi içinde sınıflandırılabilen karmaşık yaralanmalardır. Bu yaralanmalarda her bir alt tipin kendine özgü bileşenleri vardır. Kararlı bir dirsek eklemi elde etmek için bu bileşenler tam olarak tedavi edilmelidir.

\section{KAYNAKLAR}

1. GJW King. Complex dislocations of the Elbow. In: Celli A, Celli L, Morrey BF, editors. Treatment of Elbow Lesions, New Aspects in Diagnosis and Surgical Techniques. 1st ed. Italia: Springer-Verlag; 2008. p.103-12.

2. O'Driscoll SW, Jupiter JB, Cohen MS, Ring D, McKee MD. Difficult elbow fractures: pearls and pitfalls. Instr Course Lect 2003;52:113-34.

3. Ristic S, Strauch RJ, Rosenwasser MP. The assessment and treatment of nerve dysfunction after trauma around the elbow. Clin Orthop Relat Res 2000;(370):138-53.

4. Nalbantoglu U, Kocaoglu B, Gereli A, Aktas S, Guven O. Open reduction and internal fixation of Mason type III radial head fractures with and without an associated elbow dislocation. J Hand Surg Am 2007;32(10):1560-8.

5. Özkan M. Dirsek kırıklı çıkıklarında tedavi prensipleri. İçinde: Omuz ve dirsek bölgesi kırık ve çıkıkları. Kesmezacar $\mathrm{H}$, editör. İstanbul: Bayçınar Tıbbi yayıncılık ve Reklam Hizmetleri; 2010. s.141-8.

6. McKee MD, Schemitsch EH, Sala MJ, O'Driscoll SW. The pathoanatomy of lateral ligamentous disruption in complex elbow instability. J Shoulder Elbow Surg 2003;12(4):391-6.

7. Nalbantoglu U, Gereli A, Kocaoglu B, Aktas S, Turkmen M. Capitellar cartilage injuries concomitant with radial head fractures. J Hand Surg Am 2008;33(9):1602-7. CrossRef

8. Athwal GS, Ramsey ML, Steinmann SP, Wolf JM. Fractures and dislocations of the elbow: a return to the basics. Instr Course Lect 2011;60:199-214.
9. Hotchkiss RN. Displaced fractures of the radial head: Internal fixation or excision? J Am Acad Orthop Surg 1997;5(1):1-10.

10. Aksu N, Işıklar ZU. Dirsek kırıklı çıkıklarına cerrahi yaklaşım. TOTBID dergisi 2007;6(3-4):122-30.

11. Doornberg JN, de Jong IM, Lindenhovius AL, Ring D. The anteromedial facet of the coronoid process of the ulna. J Shoulder Elbow Surg 2007;16(5):667-70.

12. Doornberg JN, Ring DC. Fracture of the anteromedial facet of the coronoid process. J Bone Joint Surg Am 2006;88(10):2216-24.

13. Aksu N, Korkmaz MF, Göğüş A, Kara AN, Işiklar ZU. Surgical treatment of elbow dislocations accompanied by coronoid fractures. Acta Orthop Traumatol Turc 2008;42(4):258-64.

14. Nalbantoğlu U, Gereli A, Kocaoğlu B, Haklar U, Türkmen M. Surgical treatment of acute coronoid process fractures. Acta Orthop Traumatol Turc 2008;42(2):112-8.

15. Adams JE, Hoskin TL, Morrey BF, Steinmann SP. Management and outcome of 103 acute fractures of the coronoid process of the ulna. J Bone Joint Surg Br 2009;91(5):632-5. CrossRef

16. Regan W, Morrey B. Fractures of the coronoid process of the ulna. J Bone Joint Surg Am 1989;71(9):1348-54.

17. Adams JE, Sanches-Sotelo J, Kallina CF 4th, Morrey BF, Steinmann SP. Fractures of the coronoid: morphology based upon computer tomography scanning. J Shoulder Elbow Surg 2012;21(6):782-8. CrossRef

18. Toros T, Ozaksar K, Sügün TS, Kayalar M, Bal E, Ada S. The effect of medial side repair in terrible triad injury of the elbow. Acta Orthop Traumatol Turc 2012;46(2):96-101. CrossRef

19. Pugh DM, Wild LM, Schemitsch EH, King GJ, McKee MD. Standard surgical protocol to treat elbow dislocations with radial head and coronoid fractures. J Bone Joint Surg Am 2004;86-A(6):1122-30.

20. Konrad GG, Kundel K, Kreuz PC, Oberst M, Sudkamp NP. Monteggia fractures in adults: long-term results and prognostic factors. J Bone Joint Surg Br 2007;89(3):354-60.

21. Bado JL. The Monteggia lesion. Clin Orthop Relat Res 1967;50:71-86.

22. Ring D, Jupiter JB, Sanders RW, Mast J, Simpson NS. Transolecranon fracture-dislocation of the elbow. J Orthop Trauma 1997;11(8):545-50.

23. Doornberg J, Ring D, Jupiter JB. Effective treatment of fracture-dislocations of the olecranon requires a stable trochlear notch. Clin Orthop Relat Res 2004;(429): 292-300.

24. Jupiter JB, Leibovic SJ, Ribbans W, Wilk RM. The posterior Monteggia lesion. J Orthop Trauma 1991;5(4):395-402.

25. Tashjian RZ, Katarincic JA. Complex elbow instability. J Am Acad Orthop Surg 2006;14(5):278-86. 